\title{
EFFECTS OF CELL PHONE-EMITTED ELECTROMAGNETIC FIELD ON THE COGNITIVE FUNCTION IN YOUNG RATS: POSSIBLE ROLE OF ALPHA LIPOIC ACID SUPPLEMENTATION
}

\author{
By
}

\author{
Samar M. M. Abd El Rahman, Bataa M.A. El- Kafoury, Enas A. Abdel- \\ Hady, Noha N. Lasheen, Wesam El Bakly*, Wael M. Elayat** \\ Departments of Medical Physiology, Pharmacology* and Biochemistry** \\ Corresponding Author: Samar M.M. Abd El Rahman \\ Email: samar.m.abdelrahman@gmail.com
}

\begin{abstract}
Background: The possibility of exposure to a considerable amount of electromagnetic waves exists all around us. The hippocampus is involved in spatial memory and learning processes which could be compromised by exposure to cell phone emitted radiofrequency (RF)-electromagnetic field (EMF .(

Objective: To explore the effect of exposure to EMF on hippocampal function and to throw more attention on the mechanisms of interaction in the form of hippocampal acetylcholine (ACh), glutamate, malondialdehyde (MDA) and hippocampal cellular responses mediated by autophagy (Atg7 gene expression) and mitochondrial repair mechanism (SIRT1(

Subjects and Methods: This study was performed on 39 young apparently healthy male Wistar albino rats, initially weighing 70-90 grams. They were randomly divided into three equal groups: control group (group I), cell phone-EMF exposed group (group II), which was exposed to cell phone, 2 hours/day, 6 days/week for 12 weeks, and alpha lipoic acid-treated cell phone-exposed group (group III) which was exposed to EMF as group 2 and received i.p injection of alpha lipoic acid in a dose of $50 \mathrm{mg} / \mathrm{kg}$ for the last 3 weeks of cell phone exposure. Twelve weeks later, all rats were subjected to cognitive function test for learning and spatial memory using Morris water maze. Body weight changes and liver function tests (ALT and AST) were evaluated, then hippocampal levels of glutamate, ACh, MDA, gene expression of Atg7 and SIRT1 were measured.

Results: Compared to the control rats, cell phone exposure in group II did not alter the cognitive function test and the hippocampal glutamate level, but it caused significant rise in hippocampal MDA and acetylcholine levels, though there was a higher non- significant increased expression of SIRT1 and Atg7. Lipoic acid treatment concomitant with EMF exposure induced increase in the time spent in target quadrant with shortened time to reach the platform on fifth day of training compared to the controls. Also, lipoic acidtreated cell phone exposed rats exhibited significantly enhanced hippocampal glutamate level accompanied by significantly reduced hippocampal MDA and acetylcholine levels compared to control rats and preserved higher but non-significant levels of SIRT1 and Atg7 expression.

Conclusion: Increased hippocampal ACh and expression of SIRT1 and Atg7 could be the early protective response against the higher MDA with exposure, thereby preventing the negative impact of EMF exposure on learning and spatial memory. Lipoic acid treatment improved cognition by increasing glutamate necessary for long term potentiation and decreasing hippocampal MDA.
\end{abstract}

Key words: Cell Phone, Cognitive Function, Electromagnetic Field, Lipoic Acid, Oxidative stress. 


\section{INTRODUCTION}

The cell phone industry has undergone rapid growth. Cell phones are operating at frequencies between 450 and $2700 \mathrm{MHz}$. This range is included in radiofrequency field of non-ionizing radiation in which other devices such as Wi-Fi systems, satellite communication systems and TV stations work (Consales et al., 2012 and Kim et al., 2019). Because RF-EMF can penetrate the body cells causing vibration of charged or polar molecules in addition to both thermal and non-thermal stress, thus EMF exposure is critical to human health and safety. (D'Silva et al., 2017 and Kim et al., 2019).

Previous studies have reported several hazardous effects of cell phone radiation on different body organs such as male reproductive system (Kesari et al., 2011), thyroid gland (Baby et al., 2017), cardiovascular system (Huang et al., 2015), kidney (Deniz et al., 2017), mental health (Thomée et al., 2011) and cognition (Gupta et al., 2018).

Many controversies regarding RF-EMF exposure on the cognitive function exist. Exposure to $900 \mathrm{MHz}$ caused reduction of synapses and decreased the postsynaptic density of neuron in the hippocampus CA1 region, resulting to spatial learning and reference memory deficits in rats ( $\mathrm{Li}$ et al., 2012). Later studies demonstrated that EMF caused cognitive impairments due to reduced levels of neurotransmitters (Narayanan et al., 2015). Meanwhile, the frequency of $2450 \mathrm{MHz}$ exhibited cognitive dysfunction with hippocampal mitochondrial dysfunction, amyloid genesis and higher MDA (Gupta et al., 2018).
On the other hand, it was found that electromagnetic radiations did not alter memory of rat in spatial and non-spatial tasks (Choi \& Choi, 2016 and Son et al., 2016). EMF was suggested to be novel therapeutic approach in regenerative medicine as it increases spatial learning and memory in rats injected neurotoxic drugs (Sakhaie et al., 2017). Transgenic Alzheimer's mice with long-term RFEMF exposure for more than 8 months were reported to show improvement in cognitive abilities (Arendash et al., 2010 and Son et al., 2018).

Alpha lipoic acid (LA), also known as thioctic acid, contains two oxidized or reduced thiol groups, and it has both fatsoluble and water-soluble properties (Liu et al., 2018) The oxidized/reduced redox couple seems to be able to regenerate other antioxidants, thereby maintaining cellular antioxidant status, and thus it is called antioxidant of antioxidants (Goraca et al., 2011).

LA could improve the cognitive dysfunction significantly by its strong antioxidant effects and decreasing the oxidative stress (Mehrotra et al., 2015 and Zhang et al., 2017). Therefore, it was reported to have an important neuroprotective effect.

Sirtuin-1 (SIRT-1), NAD+-dependent protein deacetylase, is an important metabolic nuclear sensor. According to the cellular metabolic and energy status, it regulates the chromatin structure and gene expression through transcription factors, and transcription co-factors $(\mathrm{Li}, 2013)$.

Low-energy status, resulting from mitochondrial function disturbance was found to enhance the cellular NAD+ levels and stimulate SIRT1 activity. 
SIRT1 could restore mitochondrial mass, and could activate the genes transcription that regulate mitochondrial biogenesis to maintain energy and metabolic homeostasis (Li, 2013 and Dusabimana et al., 2019).

Autophagy is a protective cellular response to stresses to remove aged or dysfunctional macromolecules and organelles for maintaining cellular homeostasis. It occurs normally at low levels but is accelerated by many cellular stressors, such as DNA damage and organelle damage (Mizushima \& Levine, 2010 and Frudd et al., 2018). This entire process is controlled by group of genes called the autophagy-specific gene such as Atg 7 (Kroemer and J??ttel?, 2005).

The present study was designed to probe the effects of EMF exposure on the learning and spatial memory outcomes in young rats with more evaluation to new possible mechanisms of interaction such as levels of neurotransmitters and gene expression of SITR1 and Atg 7. The role of lipoic acid treatment on cognition and how it can alter these hippocampal genes were also going to be evaluated.

\section{SUBJECTS AND METHODS}

This study was performed on 39 apparently healthy young male Wistar rats, initially weighing 70-90 grams, purchased from Animal Farm (El-Zyad import office of experimental animals for colleges and research centers), Giza. They were maintained in the Medical Ain Shams Research Institute (MASRI), Faculty of Medicine, Ain Shams University, under standard conditions of boarding at room temperature $22-25^{\circ} \mathrm{C}$, normal light/dark cycle, and free access to food and water- ad libitum- throughout the whole period of the study. Standard rat diet was introduced daily at fixed time to the rats. All animal experiments were performed according to the National Institutes of Health guide for the care and use of Laboratory animals (NIH Publications No. 8023, revised 1978). Further, the Ain Shams Faculty of Medicine Ethical Committee approval was obtained.

Chemicals and Drugs: Alpha lipoic acid (ALA) was purchased from Sigma Aldrich Chemicals; USA and supplied as powder and kept at room temperature.

\section{Experimental Protocol:}

Rats were randomly divided into three equal groups:

Control group: received intraperitoneal (i.p.) injection of normal saline solution $(0.9 \% \mathrm{NaCl})$ in an equivalent dose to alpha lipoic acid.

Cell phone-emitted Electromagnetic Field group: Rats of this group were exposed to electromagnetic field of a single cell phone, 2 hours/day, 6 days/week for 12 weeks (Kim et al., 2017).

Alpha lipoic acid-treated Cell phoneemitted Electromagnetic Field group: Rats of this group were exposed to electromagnetic field as group 2, and received i.p injection of alpha lipoic acid in a dose of $50 \mathrm{mg} / \mathrm{kg}$ for the last 3 weeks of cell phone exposure (modified from Zhao et al., 2015). 
Technique of Exposure to Electromagnetic Field:

Second and Third groups were exposed to a radiofrequency (RF) field emitted by 900-1800 MHz frequency band (Global System for Mobile Communication (GSM) mobile phone, LG B220) at fixed time daily. The GSM cell phones operate with microwave carrier frequencies in the GHz range (850-1900 MHz) (Peter et al., 2007).

The exposure was done in special plastic cages $\left(\begin{array}{llllll}20 & \mathrm{x} & 31 & \mathrm{x} & 13.5 & \mathrm{~cm}\end{array}\right)$, 3rats/cage, the cell phone being placed under the cage by distance $0.5 \mathrm{~cm}$ (Aksen et al., 2004 and Dasdag et al., 2004), and was kept in ringing position in silent mode during the time of exposure $2 \mathrm{hrs}$./ day, 5 days/week for 12 weeks.

The intensity of electromagnetic field radiated from cell phone was 2.2 milliGauss (10 -7 Tesla) at the center of the exposure cage, as measured by Gauss/Teslameter, 4048, USA (Courtesy of Faculty of Science, Ain Shams University).

At the end of experimental period (12 weeks), all rats were subjected to behavioral test (cognitive function test).

\section{Morris Water Maze training}

The behavioral training and testing were conducted in a water maze. The water maze was a brown circular pool $(180 \mathrm{~cm}$ in diameter and $50 \mathrm{~cm}$ high) filled to a $25 \mathrm{~cm}$ depth with $22 \pm 2$ oC water (Vorhees and Williams, 2006). Atlantis platform (diameter $10 \mathrm{~cm}$ ) was placed at the center of one quadrant (North-East quadrant) of the maze and submerged $3 \mathrm{~cm}$ below the surface of the water. Water was rendered opaque by the addition of powdered milk, and the maze was in a room containing a number of constant, salient visual cues (posters, objects, and equipment). A video camera was mounted on the ceiling directly above the pool to record the swim path of each rat.

In spatial training procedure, rats received four trials in the Morris watermaze on each of 5 days of training (Anisman and McIntyre, 2002). On each trial, the rats were placed into the water at one of the four cardinal points of the compass, which varied from trial to trial in a quasi-random order. The rat had to swim until it climbed onto the escape platform. The latency was recorded till the rat reached the platform and remained on it for $10 \mathrm{sec}$. If the rat did not reach the platform within $120 \mathrm{sec}$, the trial was terminated, and the rat was placed on the platform for $10 \mathrm{sec}$. Thereafter, rats were transferred to a dry holding cage where they remained for $60 \mathrm{sec}$ until the next trial. After training, rats were returned to their home cages.

On day 6, rats were returned to the water maze for a retention test. The rats were given a 60 s probe trial during which the platform was removed. The parameters measured from probe test were the time spent $(\%)$ in each quadrant of the task.

After performing Morris water maze test, the overnight fasted rats were weighed and anesthetized by i.p. injection of Pentobarbitone, in a dose of $40 \mathrm{mg} / \mathrm{kg}$ B.W. When the stage of surgical anesthesia had been reached, judged by loss of withdrawal reflexes, a midline abdominal incision was made, and the separated plasma was used for later 
determination of liver function tests to exclude liver failure-induced rise of glutamate in the brain tissues.

Rat skull was opened, and the brain was dissected out and washed by saline. The hippocampus was reached from the medial side after division of the brain at the mid sagittal plane into right and left hemispheres, followed by removal of the whole brain stem and cerebellum (Scudamore, 2014). The right hippocampi from all studied groups were stored at $80^{\circ} \mathrm{C}$ for later determination of glutamate and acetyl choline as neurotransmitter, oxidative stress marker (MDA) and mitochondrial function.

Determination of the glutamate neurotransmitter was performed by ultrapressure liquid chromatography (UPLC), while acetyl choline was assayed in the hippocampus by Choline CompetitiveELISA Method using kits supplied by MyBioSource, USA.

Right hippocampal tissue MDA was measured by colorimetric method according to Satoh (1978) and Ohkawa et al. (1979), using kits supplied by Biodiagnostic, Egypt.

Determination of plasma Aspartate Aminotransferase (AST) and Alanine Aminotransferase (ALT) activities were performed by U.V. Kinetic method according to the International Federation of Clinical Chemistry (IFCC), using the kit supplied by Spectrum, Egypt.

\section{RNA isolation from hippocampal tissue and qRT-PCR:}

Equally weighed frozen right hippocampal tissues were homogenized and total RNA was extracted using TRIzol reagent (Invitrogen) (Fischer Scientific cat no 15596026$)$, then the concentration and purity of RNA were determined by NanoDrop 1000 spectrophotometer. One $\mu \mathrm{g}$ of RNA was reverse transcribed for cDNA synthesis with QuantiTect ${ }^{\circledR}$ Reverse Transcription kit (QIAGEN, Germany) (Cat no. 205311). Quantitative Real-time PCR (qRT-PCR) was performed for SIRT1 and Atg7 genes using Fast SYBR Green master mix (Qiagen Germany) (Cat no. 204141 ), and 5 plex rotor gene TM system (Qiagen) according to manufacturer's instructions.

The primers for Sirtulin was designed and purchased from Macrogen, (Seoul, Rep. of Korea) (accession number).

The primers sequence of this gene $(\mathrm{F}$ : TGTAGATGAGGCAGAGGTTCCC and R: ATCAGGTAGTTCCTCGGTGTCC), while Atg7 (SG quantiTect primer; cat no. 249900; Assay ID: QT0008974) (Qiagen Germany) and B-actin gene, the reference gene (HS_ACTB_1 quantiTect primer; cat no. 249900; Assay ID: QT000954 31 Qiagen Germany). The expression of the target genes was defined based on the cycle threshold $(\mathrm{Ct})$, their expression levels were calculated as $2-\Delta \Delta \mathrm{Ct}$ after normalization to relative expression of $\beta$ actin gene (Livak and Schmittgen, 2001).

\section{Statistical Analysis:}

All results in the present study were expressed as mean $\pm \mathrm{SE}$ of the mean. Latency to reach target quadrant in the 5 days, Percentage of change of latency between day 1 and day 5 of training and $\%$ of time spent in target quadrant in Day 6 were calculated by two way ANOVA using GraphPad prism, software program, version 5.0 (2007) (GRAPHPAD Inc., CA, USA). While other biochemical parameters were calculated by one-way 
ANOVA using Statistical Package for the Social Sciences (SPSS, Inc., Chicago, IL, USA) program, version 20.0. Differences were considered significant when $\mathrm{P} \leq$ 0.05 .
Correlations and Lines of Regression were calculated by linear regression analysis using the Least Square Method. A probability of $(\mathrm{P}<0.05 ; 2$ tailed $)$ was considered statistically significant.

\section{RESULTS}

Behavioral Tests (Morris Water Maze): Exposure to EMF caused insignificant change in latency to reach the platform between control and cell phone-exposed in the 5 days of the test (table 1).

By measuring the percentage of change in latency to reach platform in water maze between day 5 and day 1, among the different studied groups, there was nonsignificant change between exposed and control rats $(-48.51 \pm 14.4 \%$ in exposed versus $-37.9 \pm 12.6 \%$ in control ). On lipoic acid treatment, the $\%$ of change in time to reach the platform between first and fifth day of training reduced though non- significant compared to exposed non treated $(-80.19 \pm 4.95$ in treated versus $48.51 \pm 14.4 \%$ in exposed) and significantly reduced compared to control $(-80.19 \pm 4.95$ in treated versus $-37.9 \pm$ $12.6 \%$ in control $\mathrm{P}<0.01$ ).

Compared to the controls, cell phoneexposed group exhibited insignificantly change percent of time spent in target quadrant (in absence of platform) in day 6 . However, lipoic acid supplementation caused significant increase in the percent of time spent in target quadrant compared to that in cell phone-exposed group (30.82 \pm 1.33 in lipoic versus $23.09 \pm 0.513$ in exposed $\mathrm{P}<0.01$ ), and non-significant change compared to normal control (table 2).

Although hippocampal glutamate level insignificantly changed in cell phone- exposed group compared to the control group, lipoic acid supplementation caused a significant rise in hippocampal glutamate level in the treated group compared to the respective untreated group. On the other hand, hippocampal acetyl choline level significantly elevated in cell phone-exposed group compared to normal control, but lipoic acid supplementation caused significantly lowered hippocampal acetyl choline in the treated group compared to the respective untreated group, and was insignificantly changed when compared to the control ones (table 3).

In addition, hippocampal MDA level was significantly increased in cell phoneexposed group compared to the control group. Lipoic acid treatment is associated with significantly reduced hippocampal MDA level compared to that in cell phone exposed group without treatment. Hippocampal MDA level in treated group was insignificantly changed when compared to the control rats (table 3 ).

Regarding hippocampal gene
expression changes, there were upregulated hippocampal SIRT1 and Atg 7 genes expressions in cell phone exposed group compared to control. However, in the lipoic acid-treated group, hippocampal Atg 7 gene expression significantly upregulated compared to untreated group as well as compared to the control group. SIRT1 expression significantly increased with lipoic treatment compared to control despite being insignificantly changed 
compared to that in cell phone exposed (table 3).

Plasma ALT and AST levels insignificantly changed among the different studied groups. Similarly, initial and final body weights insignificantly changed among the different studied groups (table 4).

Correlations: Correlations studies in the three experimental rat groups revealed significant negative correlations between $\%$ of time spent in target quadrant in day 6 with hippocampal acetyl choline $(\mathrm{r}=$ $0.468, \mathrm{P}<0.01, \mathrm{n}=30$ )and significant negative correlation with MDA levels $(\mathrm{r}=$ $-0.429, \mathrm{P}<0.05, \mathrm{n}=27$ ). Also, a significant positive correlation between glutamate and the \% of change in latency to reach platform between day 1 and day 5 $(r=0.414, P<0.03, n=27)$.

Table (1): Changes in Morris Water Maze (latency to reach target quadrant in the 5 days (sec)) in the different studied groups

\begin{tabular}{|c|c|c|c|}
\hline Groups & $\begin{array}{c}\text { Control } \\
\text { group }\end{array}$ & $\begin{array}{c}\text { Cell phone- } \\
\text { emitted } \\
\text { Electromagneti } \\
\text { c Field group }\end{array}$ & $\begin{array}{c}\text { Lipoic acid- } \\
\text { treated Cell } \\
\text { phone-emitted } \\
\text { Electromagnetic } \\
\text { Field group }\end{array}$ \\
\hline $\begin{array}{c}\text { (Day 1) } \\
\text { Mean } \pm \text { SEM }\end{array}$ & $68.6 \pm 9.28$ & $71.1 \pm 10.28$ & $83.42 \pm 10.43$ \\
\hline $\begin{array}{c}\text { (Day 2) } \\
\text { Mean } \pm \text { SEM }\end{array}$ & $47.48 \pm 7.97$ & $43.31 \pm 10.81$ & $44.73 \pm 6.82$ \\
\hline $\begin{array}{c}\text { (Day 3) } \\
\text { Mean } \pm \text { SEM }\end{array}$ & $42.15 \pm 8.66$ & $32.58 \pm 8.87$ & $28.69 \pm 3.27$ \\
\hline $\begin{array}{c}\text { (Day 4) } \\
\text { Mean } \pm \text { SEM }\end{array}$ & $39.29 \pm 8.29$ & $32.71 \pm 6.57$ & $16.56 \pm 4.75$ \\
\hline $\begin{array}{c}\text { (Day 5) } \\
\text { Mean } \pm \text { SEM }\end{array}$ & $29.92 \pm 6.69$ & $29.9 \pm 8.02$ & $14.23 \pm 2.55$ \\
\hline
\end{tabular}

There were no significant difference among the three groups. 
Table (2): Changes in Morris Water Maze (percentage of change of latency between day 1 and day 5 of training and \% of time spent in target quadrant in Day 6 in the studied groups.

\begin{tabular}{|c|c|c|c|}
\hline Groups & $\begin{array}{c}\text { Control } \\
\text { group }\end{array}$ & $\begin{array}{c}\text { Cell phone- } \\
\text { emitted } \\
\text { Electromagnetic } \\
\text { Field group }\end{array}$ & $\begin{array}{c}\text { Lipoic acid- } \\
\text { treated Cell } \\
\text { phone-emitted } \\
\text { Electromagnetic } \\
\text { Field group }\end{array}$ \\
\hline $\begin{array}{c}\text { Percentage of Change of } \\
\text { Latency in Day 5 } \\
\text { Mean }\end{array}$ & & & \\
\pm SEM & -37.88 & -48.51 & -80.19 \\
P* & \pm 12.63 & \pm 14.39 & \pm 4.95 \\
P1 & & $\mathrm{NS}$ & 0.0171 \\
\% of Time Spent in & & & $\mathrm{NS}$ \\
Target Quadrant Day 6 & 29.36 & 23.09 & 30.82 \\
Mean & \pm 1.52 & \pm 0.513 & \pm 1.33 \\
$\mathbf{\text { SEM }}$ & & $\mathrm{NS}$ & $\mathrm{NS}$ \\
P* & & & 0.0147 \\
P1 & & & \\
\hline
\end{tabular}

$\mathrm{P}^{*}$ : Significance from the control group by LSD, at $\mathrm{P} \leq 0.05$.

$\mathrm{P} 1$ : Significance from cell phone-exposed single source group by LSD, at $\mathrm{P} \leq 0.05$.

NS: Not significant. 
Table (3): Hippocampal neurotransmitters and MDA, and the selected gene expressions in the studied groups.

\begin{tabular}{|c|c|c|c|}
\hline Parameters & $\begin{array}{c}\text { Control } \\
\text { group }\end{array}$ & $\begin{array}{c}\text { Cell phone- } \\
\text { emitted } \\
\text { Electromagnetic } \\
\text { Field group }\end{array}$ & $\begin{array}{c}\text { Lipoic acid- } \\
\text { treated Cell } \\
\text { phone-emitted } \\
\text { Electromagnetic } \\
\text { Field group } \\
\end{array}$ \\
\hline $\begin{array}{c}\text { Hippocampal } \\
\text { Glutamate Level } \\
\text { (nmole/ml) } \\
\text { Mean } \\
\pm \text { SEM } \\
\text { P* } \\
\text { P1 }\end{array}$ & $\begin{array}{l}496.26 \\
\pm 50.49\end{array}$ & $\begin{array}{c}651.19 \\
\pm 52.18 \\
\text { NS }\end{array}$ & $\begin{array}{l}863.21 \\
\pm 73.7 \\
<0.001 \\
<0.02\end{array}$ \\
\hline $\begin{array}{c}\text { Hippocampal Acetyl } \\
\text { Choline level (ng /mg } \\
\text { protien) } \\
\text { Mean } \\
\pm \text { SEM } \\
\text { P* } \\
\text { P1 } \\
\end{array}$ & $\begin{array}{l}2.12 \\
\pm 0.2\end{array}$ & $\begin{array}{c}5.92 \\
\pm 0.46 \\
<0.001\end{array}$ & $\begin{array}{c}2.78 \\
\pm 0.18 \\
\mathrm{NS} \\
<0.001\end{array}$ \\
\hline $\begin{array}{c}\text { Hippocampal } \\
\text { Malondialdehyde } \\
\text { (MDA) level (nmol / } \\
\text { gram tissue) } \\
\text { Mean } \\
\pm \text { SEM } \\
\text { P* } \\
\text { P1 }\end{array}$ & $\begin{array}{l}141.74 \\
\pm 18.5\end{array}$ & $\begin{array}{l}213.79 \\
\pm 33.36 \\
<0.05\end{array}$ & $\begin{array}{c}124.9 \\
\pm 11.66 \\
\mathrm{NS} \\
<0.01\end{array}$ \\
\hline $\begin{array}{c}\text { SIRT1 gene } \\
\text { expression (copy) } \\
\text { Mean } \\
\pm \text { SEM } \\
\text { P }^{*} \\
\text { P1 }\end{array}$ & $\begin{array}{c}1.08 \\
\pm 0.06\end{array}$ & $\begin{array}{c}2.15 \\
\pm 0.4 \\
\mathrm{NS}\end{array}$ & $\begin{array}{l}2.88 \\
\pm 0.11 \\
<0.005 \\
\quad \mathrm{NS}\end{array}$ \\
\hline $\begin{array}{c}\text { Atg } 7 \text { gene expression } \\
\text { (copy) } \\
\text { Mean } \\
\pm \text { SEM } \\
\text { P* }^{*} \\
\text { P1 }\end{array}$ & $\begin{array}{c}1.06 \\
\pm 0.07\end{array}$ & $\begin{array}{c}1.46 \\
\pm 0.15 \\
\text { NS }\end{array}$ & $\begin{array}{l}4.45 \\
\pm 0.64 \\
<0.001 \\
<0.001\end{array}$ \\
\hline
\end{tabular}

$\mathrm{P}^{*}$ : Significance from the control group by LSD, at $\mathrm{P} \leq 0.05$.

$\mathrm{P} 1$ : Significance from cell phone-exposed single source group by LSD, at $\mathrm{P} \leq 0.05$.

NS: Not significant. 
Table (4): Changes in plasma levels of AST and ALT, and body weight (initial body weights and final body weights) in the studied groups.

\begin{tabular}{|c|c|c|c|}
\hline Parameters & $\begin{array}{c}\text { Control } \\
\text { group }\end{array}$ & $\begin{array}{c}\text { Cell phone- } \\
\text { emitted } \\
\text { Electromagnetic } \\
\text { Field group }\end{array}$ & $\begin{array}{c}\text { Lipoic acid-treated } \\
\text { Cell phone-emitted } \\
\text { Electromagnetic } \\
\text { Field group }\end{array}$ \\
\hline $\begin{array}{c}\text { Plasma AST Level (U/L) } \\
\text { Mean }\end{array}$ & 59.1 & 62.66 & 60.76 \\
\pm SEM & \pm 4.86 & \pm 6.67 & \pm 5.17 \\
\hline $\begin{array}{c}\text { Plasma ALT Level (U/L) } \\
\text { Mean }\end{array}$ & 26.98 & 26.86 & 22.87 \\
\pm SEM & \pm 3.84 & \pm 5.67 & \pm 2.14 \\
\hline Initial Body Weight (g) & & & 76.92 \\
Mean & 75.85 & 74.38 & \pm 1.61 \\
\hline SSEM & \pm 1.62 & \pm 1.22 & 200.31 \\
\hline Final Body Weight (g) & & & \pm 8.38 \\
Mean & 200 & 204.23 & \pm 8.29 \\
\pm SEM & \pm 11.44 & & \\
\hline
\end{tabular}

There is no significant difference among the three groups.

\section{DISCUSSION}

Effects of exposure to cell phone emitted EMF on biological systems have been the subject of debate over past few decades. This study aimed to probe the effects of cell phone-emitted EMF on the cognitive functions specially the memory and learning. The hippocampus, a curved paired structure located in the temporal lobes near the amygdala, is mainly involved in new memories and spatial navigation and is also associated with learning and emotions (Deng et al., 2010 and Eichenbaum \& Cohen, 2014). EMF exposure might induce various neurological changes, but there is very limited information on what biological mechanisms influence neuronal cells of the brain in response to RF-EMF. In this study, we targeted the hippocampal structure and its content of glutamate and acetylcholine, as well as oxidative stress marker (hippocampal MDA) and hippocampal cellular responses by autophagy (Atg7 gene expression) and mitochondrial repair mechanism (SIRT1 gene expression) in a trial to explore the interactive mechanisms. Lipoic acid, the antioxidant of antioxidants, was reported to have neuro-protective effects in rats' cerebral cortex (Yang et al., 2015). The interactive mechanisms rather than its antioxidant characters were studied. The performance of rats in Morris water maze was used in this study as it was described to be a key technique in the investigation of hippocampal circuitry and spatial learning and memory (Vorhees and Williams, 2006).

In this study, non-significant changes in weight gain were observed in the three studied groups. This finding was inconsistent with other studies in which EMF decreased weight gain which was attributed to stress (Usikalu et al., 2012 and Liu et al., 2015). This may be 
attributed to variation between handling and habituation of the rats from this study to other studies. Also, non-significant changes were observed in liver function tests, namely ALT, AST, between the studied groups which were measured to exclude the effect of EMF on liver and, in turn, on glutamate level. Other studies showed non-obvious changes in liver AST and ALT with exposure of rats to 900 $\mathrm{MHz}$ cell phone radiation (Sani et al., 2018), while other studies showed significant increase with 6 months of exposure (El-Bediwi et al., 2011). The difference in duration of exposure may explain this discrepancy between the results.

In this study, the result of Morris water maze experiment, a test for learning ability and spatial memory in rodents, all rats in all groups showed a decrease in latency of escape to the platform throughout the five days of training indicating success of training.

EMF-exposed group exhibited nonsignificant change in time of latency to reach to the platform compared to control rats and on reaching the fifth day of training, which indicated no change in learning ability on exposure.

In addition, the probe test in 6th day of training examining the spatial memory showed non-significant change in the $\%$ of time spent in the target quadrant, in absence of platform, between the exposed group and the control rats indicating, also, no impairment in consolidation of memory.

In this study, the non -significant differences in cognitive function of exposed group either during acquisition (learning) or during probe test (memory retention) was observed previously. Similarly, there was no effect of exposure to $900 \mathrm{MHZ}$ or $950 \mathrm{MHz}$ of cell phone on acquisition or consolidation of spatial navigation of rats in radial radial-arm maze (Ammari et al., 2008), or by the water maze (Jadidi et al., 2009). Also, cell phone electromagnetic field has no effect on human brain bioelectric activity (Kaneta et al., 2017).

Cell phone-exposed animals had significantly $(\sim 3$ times $)$ higher mean latency to reach the target quadrant and spent significantly ( $\sim 2$ times) less time in the target quadrant than matched together with morphological changes in hippocampus (Narayanan et al., 2009 and Narayanan et al., 2015), and pyramidal neuronal loss in rats occurring with 60 days exposure to $900 \mathrm{MHZ}$ (Kerimoglu et al., 2016). EMF of $916 \mathrm{MHz}$ in? uenced learning and memory in rats to some extent in a period during exposure, and the rats were adapted to long-term EMF exposure (Hao et al., 2013) impaired cognitive function with EMF- $2450 \mathrm{MHZ}$ (Gupta et al., 2018). However, the intensity and /or the duration of exposure were different. Moreover, other studies showed that long-term exposure to RFEMF might exert beneficial effects on Alzheimer's disease in mice (Son et al., 2018).

Also, the non-impairment of learning and memory with exposure contradicted with the significantly higher hippocampal MDA level, an indicator of oxidative stress. Increased MDA with EMF exposure were found in many other studies (Kerman \& Senol, 2012 and Kerimoglu et al., 2016). The nearly normal cognitive function in the cell 
phone exposed rats, herein, compared to the controls, could be referred to the possible associated increased adaptation and body response which could be suggested to overcome the deleterious effects of ROS. This assumption could be supported by the manifested increased though non-significant SIRT-1 protein activity compared to control. The activity of SIRT-1 protein (Silent information regulator) which is an important metabolic nuclear sensor showed to increase with mitochondrial function disturbance due to oxidative stress as the level of NAD+ increased. This protein activates the transcription genes that regulate mitochondrial biogenesis to maintain energy and metabolic homeostasis (Dusabimana et al., 2019). Evidence from in vivo and in vitro studies revealed that SIRT1 regulates axon elongation, dendritic branching, synaptic plasticity was implicated in protection of neurons from degeneration in models of neurological diseases, such as traumatic brain injury and Alzheimer's disease (Fujita and Yamashita, 2018). The increased expression of gene Atg7 compared to control rats tough nonsignificant. Atg7 is a gene required for conventional autophagy, a process that is accelerated by many cellular stressors, and aims to remove aged or dysfunctional macromolecules and organelles for maintaining cellular homeostasis (Frudd et al., 2018).

The assumption of body adaptation to stress of EMF exposure was reported another study in which electric activity of brain was recorded in the same time of performing cognitive function test. Signi? cant differences in behavioral test were reported in rats during the middle period of the exposure rather than the beginning and end periods. Thus, neural reorganization was suggested to occur during recovery to the extent that different strategies and even brain areas could be able to compensate for what had been a de? cit induced by EMF (Hao et al., 2013).

Increased hippocampal acetylcholine with EMF in the exposed group, herein, could be attributed to the effects of training in first 5 days where hippocampal ACh release was reported to be increased during performance of a learned spatial task (Ragozzino et al., 1999). The increased ACh level could be related to the EMF exposure itself. Although the significant increased ACh with EMF exposure was unable to alter learning or spatial memory positively or negatively except for slightly observed better learning on day 3 and 4 of training. It could be suggested from the results of our study that this high level may be one of the early responses which was just enough to prevent the impairment rather than to increase cognition.

On the other hand, lipoic acid treatment enhanced both the learning ability and spatial memory as manifested in the significant shorter latency of escape as indicated by in higher $\%$ of decrease in time of training compared to first day and significant higher $\%$ of spent in target quadrant respectively. Also, lipoic acid treatment caused a significant increase in hippocampal glutamate level, and significant decrease in $\mathrm{ACh}$ level when compared to the exposed untreated group.

The increased glutamate with lipoic acid treatment might explain the significant better spatial memory. In normal healthy individuals, glutamatergic 
neurotransmission acts via both NMDA and AMPA receptors to produce longterm synaptic potentiation and learning via (LTP) strengthening of synapses through repeated use which is central to the processes of learning and memory (Tai \& Leung , 2012). Released glutamate was reported to bind with its AMPA and NMDA receptors at postsynaptic membrane causing membrane depolarization and calcium influx which in turn activates calcium / calmodulin dependent kinases inducing transcription for the gene of brain derived neurotrophic factor which is essential for neural survival, plasticity and long term potentiation (Marosi \& Mattson, 2014). Also, the role of glutamate in explaining better learning with lipoic treatment could be deduced from the positive significant correlation between glutamate and the shorter latency on the fifth day of training $(\mathrm{r}=0.414, \mathrm{p}<0.03, \mathrm{n}=27)$. Alpha-lipoic acid was reported to protect against glutamate-induced cytotoxicity in C6 glioma cells (Park et al., 2019).

The significant decrease in ACh could be also attributed to glutamate effect for the benefit of consolidation of memory. A significant negative correlation was observed between ACh hippocampal level and $\%$ of time spent in target quadrant Cholinergic neurons that innervate the neocortex and hippocampus are located in the basal forebrain, the activity of these cholinergic neurons is likely to be regulated by glutamatergic inputs from regions such as the amygdala, the brainstem reticular formation, the hippocampus and the cerebral cortex (Carnes et al., 1990).
Glutamate was proposed to regulate $\mathrm{ACh}$ release through a direct and an indirect via a g-aminobutyric acid inhibitory interneuron pathway (Ihalainen et al., 2011).

In addition, increased cognitive function with lipoic acid-treated EMFexposed rats could be attributed to its effect in reducing hippocampal MDA level significantly compared to the exposed group. This could be supported by the significant negative correlation between MDA and \% of time spent at target quadrant. Lipoic acid has been used as a drug to improve age -associated cognitive deficits and degenerative process in neurons (Bilska \& Wlodek, 2005 and Shay et al., 2009), and it improves the cognitive dysfunction by reducing hippocampal MDA (Zhang et al., 2017).

Lipoic acid treated group exhibited the same high level in gene expressions of SIRT1 and Atg7 nearly as the exposed group, but higher than that of control ones. This could be suggested as another supportive mechanism for the improved cognition. Similarly, lipoic acid showed to protect the mouse brain against ischemic damage, which was suggested to be through up-regulation of SIRT1 (Fu et al., 2014). SIRT1 gene expression here exhibited negative significant correlation with MDA and thus, it could be considered as one of the defense mechanisms against MDA (Zhang et al., 2017).

\section{CONCLUSION}

Exposure to mobile phone emitted EMF did not alter the cognitive function by increasing hippocampal $\mathrm{ACh}$ and both 
SIRTI \& ATG7 expression in face of higher hippocampal MDA. Lipoic treatment improved learning and spatial memory via increasing hippocampal glutamate and reducing ACh for consolidation of memory in the presence of higher SIRT1 and ATG7.

\section{REFERENCES}

1. Aksen, F., Dasdag, S., Akdag, M.Z., Askin, M. and Dasdag, M.M. (2004): The effects of whole-body cell phone exposure on the $t 1$ relaxation times and trace elements in the serum of rats. Electromagnetic Biology and Medicine, 23(1): 7-17.

2. Ammari, M., Jacquet, A., Lecomte, A. Sakly, M., Abdelmelek, H. and de Seze, R. (2008): Effect of head-only sub-chronic and chronic exposure to $900-\mathrm{MHz}$ GSM electromagnetic fields on spatial memory in rats. Brain Injury, 22(13-14):1021-1029.

3. Anisman, H . and McIntyre, D.C. (2002): Conceptual, spatial, and cue learning in the Morris water maze in fast or slow kindling rats: attention deficit comorbidity. The Journal of Neuroscience, 22(17):7809-17.

4. Arendash, G. W., Sanchez-Ramos, J., Mori, T., Mamcarz, M., Lin, X.,Runfeldt, M., Wang, L., Zhang, G., Sava, V., Tan, J. and Cao, C. (2010): Electromagnetic field treatment protects against and reverses cognitive impairment in Alzheimer's disease mice. Journal of Alzheimer's Disease, 19: 191-210.

5. Baby, N.M., Koshy, G. and Mathew, A. (2017): The Effect of Electromagnetic Radiation due to Mobile Phone Use on Thyroid Function in Medical Students Studying in a Medical College in South India. Indian Journal of Endocrinology and Metabolism, 21: 797-802.

6. Bilska, A. and Wlodek, L. (2005): Lipoic acid - the drug of the future? Pharmacological Reports, 57: 570-577.

7. Carnes, K.M., Fuller, T.A. and Price, J.L. (1990): Sources of presumptive glutamatergic/aspartatergic afferents to the magnocellular basal forebrain in the rat. The Journal of Comparative Neurology, 302(4): 824-852.

8. Choi, Y.J. and Choi, Y.S. (2016): Effects of Electromagnetic Radiation from Smartphones on Learning Ability and Hippocampal Progenitor Cell Proliferation in Mice. Osong Public Health Res Perspectives, 7(1): 12-17.

9. Consales, C., Merla, C., Marino, C., and Benassi, B. (2012): Electromagnetic Fields, Oxidative Stress, and Neurodegeneration. International Journal of Cell Biology, 2: 16.

10. Dasdag S., Akdag M.Z., Aksen F., Bashan M. and Buyukbayram H. (2004): Does 900 MHz GSM mobile phone exposure affect rat brain. Electromagnetic Biology and Medicine, 23(3): 201-214.

11. Deng, W., Aimone, J.B. and Gage, F.H. (2010): New neurons and new memories: how does adult hippocampal neurogenesis affect learning and memory? Nature Reviews Neuroscience, 11(5):339-50.

12. Deniz, ?.G., K2rrak, E.G., Kaplan, A.A. and Altunkaynak, B.Z . (2017): Effects of folic acid on rat kidney exposed to $900 \mathrm{MHz}$ electromagnetic radiation. Journal of Microscopy and Ultrastructure, 5: 198-205.

13. D'Silva, M.H., Swer, R.H., Anbalagan, J. and Rajesh, B. (2017): Effect of Radiofrequency Radiation Emitted from $2 \mathrm{G}$ and 3G Cell Phone on Developing Liver of Chick Embryo - A Comparative Study. Journal of Clinical and Diagnostic Research, 11(7): AC05-AC09.

14. Dubreuil, D., Jay, T. and Edeline, J. M. (2003): Head-only exposure to GSM 900$\mathrm{MHz}$ electromagnetic fields does not alter rat's memory in spatial and non-spatial tasks. Behavioural Brain Research, 145: 51-61.

15. Dusabimana, T., Kim, S.O., Kim, H.J., Park, S.W. and Kim, H. (2019): Nobiletin ameliorates hepatic ischemia and reperfusion injury through the activation of SIRT1/FOXO3a-mediated autophagy and mitochondrial biogenesis. Experimental \& Molecular Medicine, 51(4): 51-67

16. Eichenbaum, H. and Cohen, N.J. (2014): Can we reconcile the declarative memory and 
spatial navigation views on hippocampal function? Neuron, 83(4): 764-70.

17. El-Bediwi, A., El-kott, A.F., Saad, M. and Eid, E. (2011): Effects of Electromagnetic Radiation Produced by Mobile Phone on Some Visceral Organs of Rat. Journal of Medical Sciences, 11 (6): 256-260

18. Frudd, K., Burgoyne, T. and Burgoyne, J.R. (2018): Oxidation of Atg3 and Atg7 mediates inhibition of autophagy. Nature Communications , (9), Article number: 95.

19. Fu, H., Jin, M., Ju, L., Mao,Y. and Gao, H. (2014): Evidence for function overlapping of CymA and the cytochrome bc1 complex in the Shewanella oneidensis nitrate and nitriterespiration. Environmental. Microbiology, 16: 3181-3195.

20. Fujita, Y. and Yamashita ,T. (2018): Sirtuins in Neuroendocrine Regulation and Neurological Diseases. Frontiers of Neuroscience, 12:778.

21. Goraca, A., Huk-Kolega, H., Piechota, A., Kleniewska, P., Ciejka, E. and Skibska, B. (2011): Lipoic acid - biological activity and therapeutic potential. Pharmacological Reports, 63: 849-858.

22. Gupta, S.K., Mesharam, M.K. and Krishnamurthy, S. (2018): Electromagnetic radiation $2450 \mathrm{MHz}$ exposure causes cognition deficit with mitochondrial dysfunction and activation of intrinsic pathway of apoptosis in rats. Journal of Biosciences , 43(2): 263-276.

23. Hao, D., Yang, L., Chen, S., Tong, J., Tian, Y., Su, B., Wu, S. and Zeng, Y. (2013): Effects of long-term electromagnetic field exposure on spatial learning and memory in rats. Neurological Science, 34(2):157-64.

24. Huang, D., Dong, Z.F., Chen, Y., Wang, F.B., Wei, Z., Zhao, W.B., Li, S., Liu, M. Y., Zhu, W., Wei, M. and Li, J. B. (2015): Interference of GSM Mobile Phones With Communication Between Cardiac Rhythm Management Devices and Programmers:A Combined In Vivo and In Vitro Study. Bio electromagnetics, 36: 367-376.

25. Ihalainen, J., Saraj?rvi, T., Rasmusson, D., Kemppainen, S., Keski-Rahkonen, P.,
Lehtonen, M., Banerjee, P.K., Semba, K. and Tanila, H. (2011): Effects of memantine and donepezil on cortical and hippocampal acetylcholine levels and object recognition memory in rats. Neuropharmacology, 61(56): 891-9.

26. Jadidi, M., Firoozabadi, S.M. and Rashidy-Pour, A. (2009): Does whole body exposure to GSM-950 MHz electromagnetic fields affect acquisition and consolidation of spatial information in rats? International Journal of Radiation Research , 7(1): 57-62.

27. Kaneta, L.A. and Watson, A.L. (2017): The Effect of Mobile Telephone Electromagnetic Field on Human Brain Bioelectric Activity and Information Processing Speed. Psychology and Cognitive Sciences, 3(4): 105-109.

28. Kerimoğlu, G., Mercantepe, T., Erol, HS., Turgut, A ., Kaya, H., Çolakoğlu, S. and Odac?, E - (2016): Effects of long-term exposure to 900-megahertz electromagnetic field on heart morphology and biochemistry of male adolescent rats. Biotechnic \& Histochemistry, 91(7):445-454.

29. Kerman, M. and Senol, N. (2012): Oxidative stress in hippocampus induced by $900 \mathrm{MHz}$ electromagnetic field emitting mobile phone: Protection by melatonin. Biomedical Research, 23 (1): 147-151

30. Kesari, K.K., Kumar, S. and Behari, J. (2011): Effects of Radiofrequency Electromagnetic Wave Exposure from Cellular Phones on the Reproductive Pattern in Male Wistar Rats. Biotechnology and Applied Biochemistry, 164: 546-559.

31. Kim, J.H., Lee, J.K., Kim, H.G. , Kim, K.B. and Kim, H.R. (2019): Possible Effects of Radiofrequency Electromagnetic Field Exposure on Central Nerve System. Biomolecules and Therapeutics, 27(3): 265275.

32. Kim, J.H., Yu, D.H., Kim, H.J., Huh, Y.H., Cho, S.W., Lee, J.K., Kim, H.G. and Kim, H.R. (2017): Exposure to $835 \mathrm{MHz}$ radiofrequency electromagnetic field induces autophagy in hippocampus but not in brain stem of mice. Toxicology and Industrial Health , 34(1): 23-35. 
33. Kroemer, G. and J??ttel?, M. (2005): Lysosomes and autophagy in cell death control. Nature Reviews Cancer , 5(11): 88697.

34. Lai, H., Carino, M. A., and Ushijima, I. (1998): Acute exposure to a $60 \mathrm{~Hz}$ magnetic field affects rats' water-maze performance. Bio electromagnetics , 19: 117-122.

35. Li, X. (2013): SIRT1 and energy metabolism. Acta Biochimica et Biophysica Sinica, 45: $51-60$

36. Li, Y., Shi, C., Lu, G., Xu, Q. and Liu, S. (2012): Effects of electromagnetic radiation on spatial memory and synapses in rat hippocampal CA1 . Neural Regeneration Research , 7(16): 1248-1255.

37. Liu, J.L., Fan, Y.G., Yang, Z.S., Wang, Z.Y. and Guo, C. (2018): Iron and Alzheimer's Disease: From Pathogenesis to Therapeutic Implications. Frontiers in science, 12: 632.

38. Livak, K.J. and Schmittgen, T.D. (2001): Analysis of relative gene expression data using real-time quantitative PCR and the 2(Delta Delta C(T)) Method. Methods, 25(4): 402-8.

39. Marosi, K . and Mattson, M.P. (2014): BDNF mediates adaptive brain and body responses to energetic challenges. Trends in Endocrinology and Metabolism, 25(2): 8998.

40. Mehrotra, A., Kanwal, A., Banerjee, S.K. and Sandhir, R. (2015): Mitochondrial modulators in experimental Huntington's disease: reversal of mitochondrial dysfunctions and cognitive deficits. Neurobiology of Aging, 36(6): 2186-2200.

41. Mizushima, N. and Levine, B. (2010): Autophagy in mammalian development and differentiation. Nature Cell Biology, 12(9): 823-30.

42. Narayanan, S.N., Kumar, R.S., Karun, K.M., Nayak, S.B. and Bhat, P.G. (2015): Possible cause for altered spatial cognition of prepubescent rats exposed to chronic radiofrequency electromagnetic radiation. Metabolic Brain Disease, 30(5): 1193-1206.
43. Narayanan, S.N., Kumar, R.S., Potu, B.K., Nayak, S. and Mailankot, M. (2009): Spatial memory performance of Wistar rats exposed to mobile phone. Clinics, 64:231-4.

44. Ohkawa, H., Ohishi, N. and Yagi, K. (1979): Assay for lipid peroxides in animal tissues by thiobarbituric acid reaction. Analytical Biochemistry, 95(2): 351-8.

45. Park, E. , Gim, J., Kim, D.K. , Kim, C.S. and Chun H.S. (2019): Protective Effects of Alpha-Lipoic Acid on Glutamate-Induced Cytotoxicity in C6 Glioma Cells. The Pharmaceutical Society of Japan, 42: 94-102

46. Peter, A.V., Emilie, V.D. and Michael, H.R. (2007): Workgroup report: Base stations and wireless networksradiofrequency (RF) exposures and health consequences. Environ. Health Perspect, 115: 416-424.

47. Ragozzino, M.E., Wilcox, C., Raso, M. and Kesner, R.P. (1999): Involvement of rodent prefrontal cortex subregions in strategy switching. Behavioral Neuroscience, 113:3241.

48. Sakhaie, M.H., Soleimani, M., Pourheydar, M., Majd, Z., Atefimanesh, P., Asl, S.S. and Mehdizadeh, M. (2017): Effects of Extremely Low-Frequency Electromagnetic Fields on Neurogenesis and Cognitive Behavior in an Experimental Model of Hippocampal Injury. Behavioural Neurology; Article ID 9194261, 9 pages.

49. Sani, A., Labaran, M.M. and Dayyabu, B. (2018): Effects of Electromagnetic Radiation of Mobile Phones on Hematological and Biochemical Parameters in Male Albino Rats. European Journal of Experimental Biology, 8: 2-11.

50. Satoh, K. (1978): Serum lipid peroxide in cerebrovascular disorders determined by a new colorimetric method. Clinica Chimica Acta; International Journal of clinical Chemistry, 90(1):37-43.

51. Scudamore CL. (2014): A practical guide to the histology of the mouse. 1st edition.p61 Wiley Blackwell. John Wiley and Sons, Ltd. Laserwords private, P.(17- 18) Chennai, India. 
52. Shay, K.P., Moreau, R.F., Smith, E.J., Smith. A.R. and Hagen, T.M. (2009): Alpha-lipoic acid as a dietary supplement: Molecular mechanisms and therapeutic potential. Biochimica et Biophysica Acta (BBA), 1790(10): 1149-1160.

53. Son, Y., Jeong, Y. J., Kwon, J. H., Choi, H. D., Pack, J. K., Kim, N., Lee, Y. S. and Lee, H. J. (2016): 1950MHz radiofrequency electro-magnetic fields do not aggravate memory deficits in 5xFAD mice. Bio electromagnetics, 37: 391-399.

54. Son, Y., Kim, J. S., Jeong, Y. J., Jeong, Y. K., Kwon, J. H., Choi, H. D., Pack, J.K., Kim, N., Lee, Y.S. and Lee, H.J. (2018): Long-term RF exposure on behavior and cerebral glucose metabolism in $5 x F A D$ mice. Neuroscience Letters, 666: 64-69.

55. Tai, S.K. and Leung, L.S.( 2012): Vestibular stimulation enhances hippocampal long-term potentiation via activation of cholinergic septohippocampal cells. Behavioural Brain Research, 232(1) : 174182.

56. Thomée, S., H?renstam, A. and Hagberg, M. (2011): Mobile phone use and stress, sleep disturbances, and symptoms of depression among young adults - a prospective cohort study. BMC Public Health, 11: 66-76, u-Jin Choi, u-Jin Choi

57. Usikalu, M.R., Rotimi, S.O. and Oguegbu, A. E. (2012): Effect of Exposure of $900 \mathrm{MHz}$ Radiofrequency Radiation on Rat Brain. European Journal of Experimental Biology, 2 (6): 2499-2504.

58. Vorhees, C.V. and Williams, M.T. (2006): Morris water maze: procedures for assessing spatial and related forms of learning and memory. Nature Protocol, 1(2):848-58.

59. Wyde, M. E., Horn, T. L., Capstick, M H., Ladbury, J M., Koepke, G., Wilson, P. F., Kissling, G. E., Stout, M.D., Kuster, N., Melnick, R. L.,Gauger, J., Bucher, J. R. and McCormick, D.L. (2018): Effect of Cell Phone Radiofrequency Radiation on Body Temperature in Rodents: Pilot Studies of the National Toxicology Program's Reverberation Chamber Exposure System. Bio electromagnetics, 39: 190-199.

60. Yang, T.Y., Xu, Z.F., Liu, W., Xu, B., Deng, Y., Li, Y.H. and Feng, S. (2015): Alpha lipoic acid protects against methylmercury-induced neurotoxic effects via inhibition of oxidative stress in rat cerebral cortex. Environmental Toxicology and Pharmacology, 39: 157-166.

61. Zhang, L., Tu, R., Wang, Y., Hu, Y., Li, X., Cheng, X., Yin, Y., Li, W. and Huang, H. (2017): Early-Life Exposure to Lead Induces Cognitive Impairment in Elder Mice Targeting SIRT1 Phosphorylation and Oxidative Alterations. Frontiers in Physiology, 8: 446.

62. Zhang, Q., Kong, M., Li, H., Li, J., Zhang, H. and Zhang, S. (2017): Effect of alpha lipoic acid on cognitive function and oxidative stress in STZ diabetic rats. Biomedical Research, 28 (12): 5229-5232.

63. Zhao, R.R., Xu, F., Xu, X.C., Tan, G.J., Liu, L.M., Wu, N ., Zhang, W.Z . and Liu, J.X - (2015): Effects of alpha-lipoic acid on spatial learning and memory, oxidative stress, and central cholinergic system in a rat model of vascular dementia. Neuroscience Letters , 587:113-9 


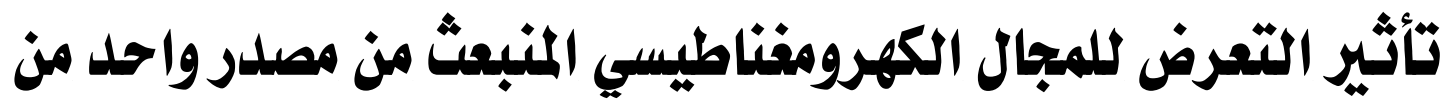

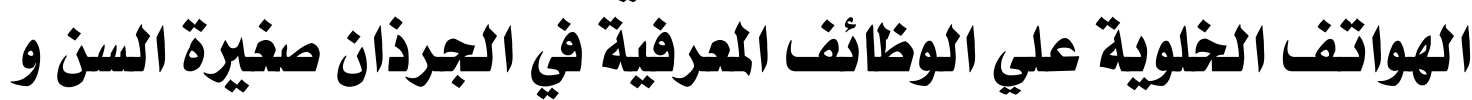

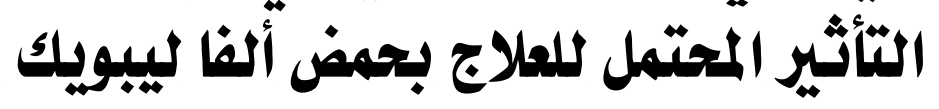

سمر محمود محمود عبد الرحمن - باتعه محمد علي الكافوري - إيناس عبد العزيز

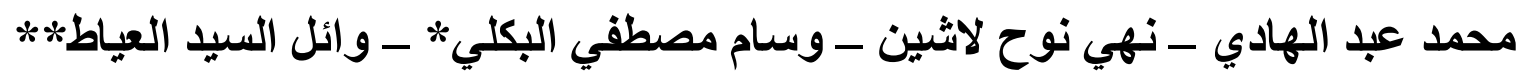
أقسام الفسيولوجيا الاكلينكية و الفارماكولوجي* و الكيمياء الحيوية*** ـ كليه الطب - جامعة عين شمس

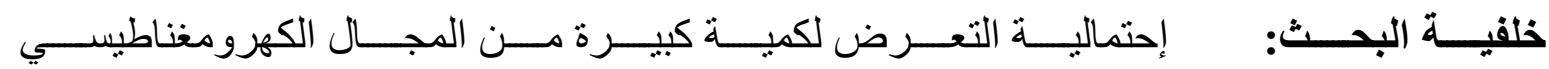

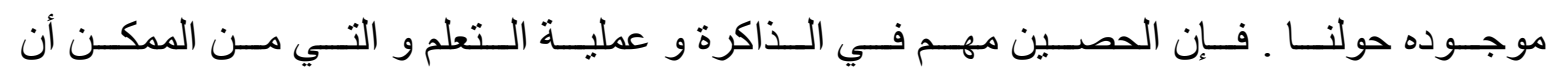
تتأثر بالتعرض للمجالات الكهرومغناطيسية المنبعثة من الهاتف الخلوي.

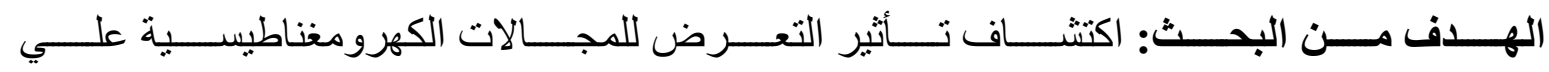

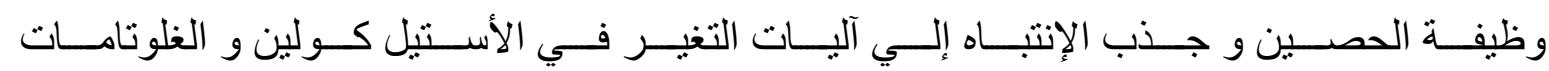
و دلالات الإجهاد التأكسدي في أنسجة المخ و التغييرات الجينية في الحصين.

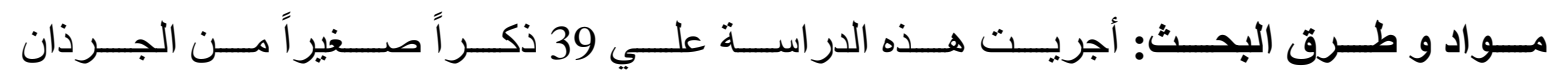

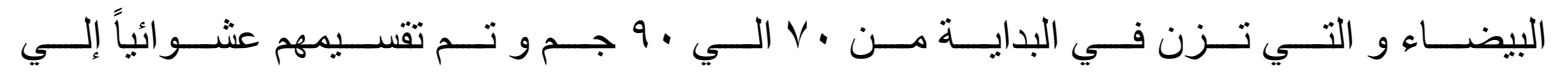

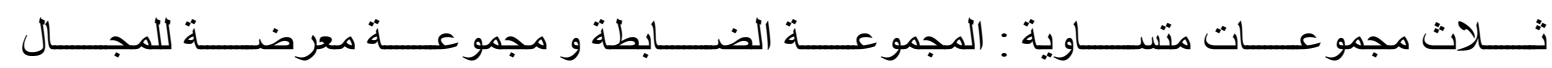

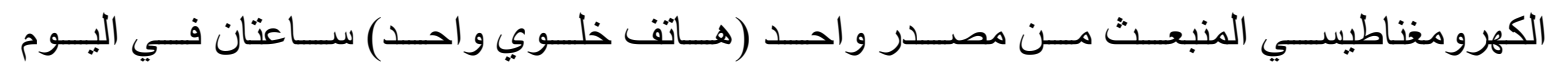

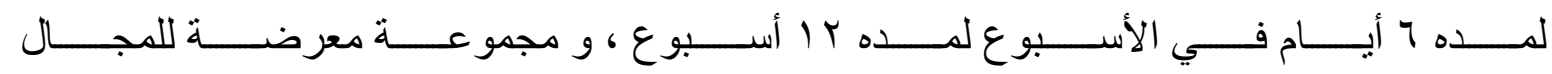

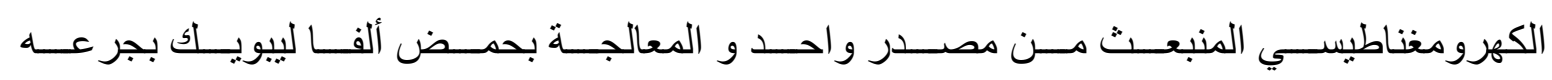

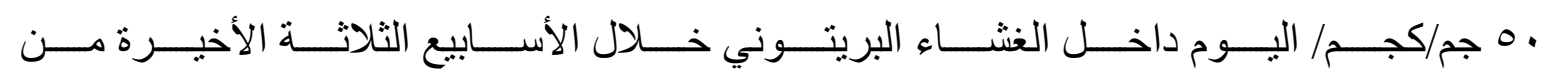
التعرض للهاتف الخلوي.

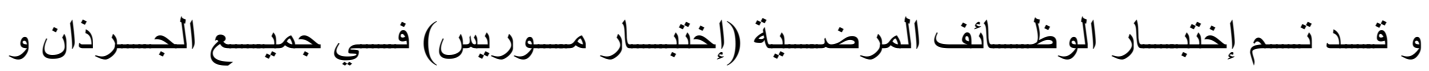

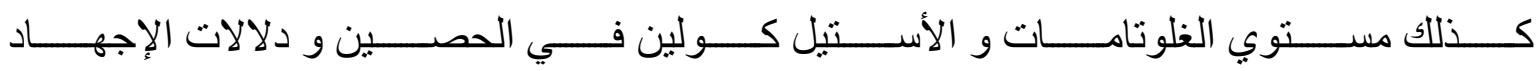
التأكسدي في المخ و التغييرات الجينية في الحصين و بعض وظائف الكبد.

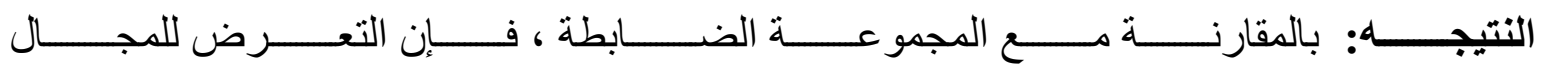

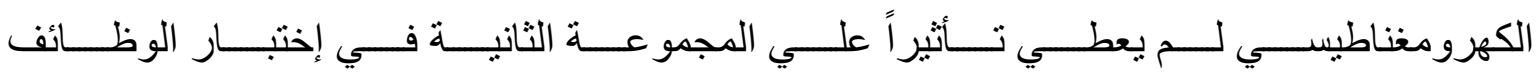




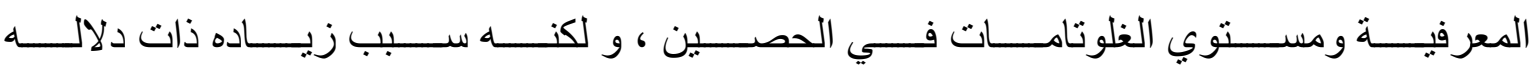

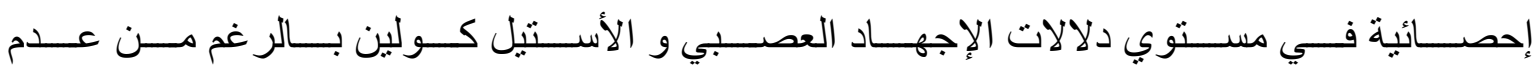

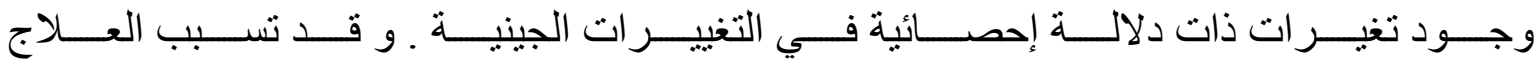

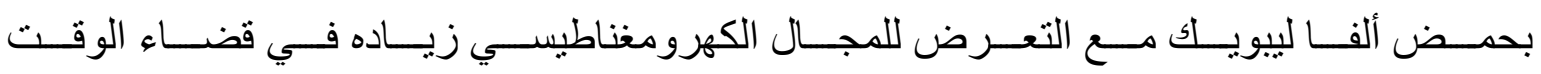

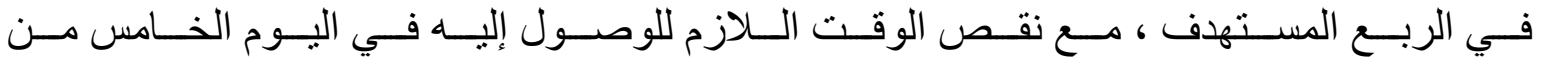

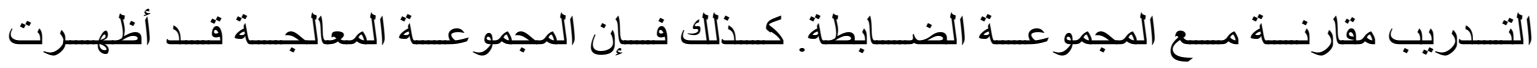

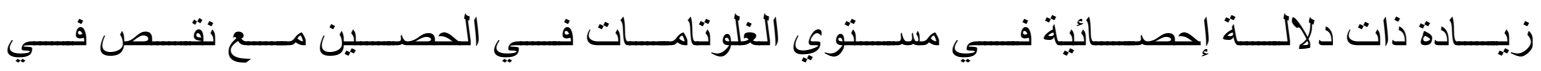

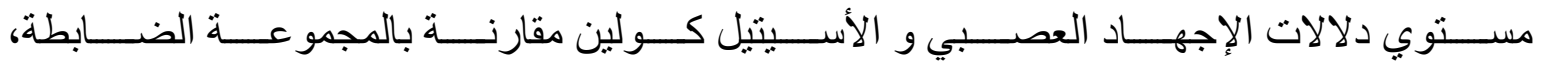
بالإضافة إلي عدم وجود تغير جيني ذو دلالة إحصائية .

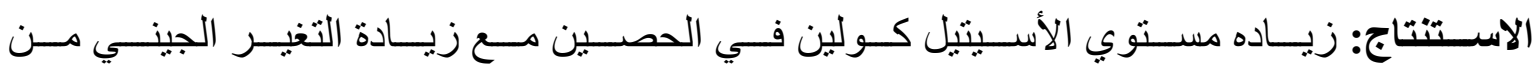

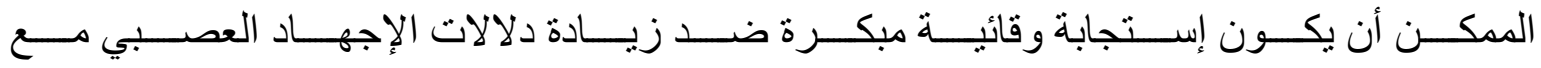

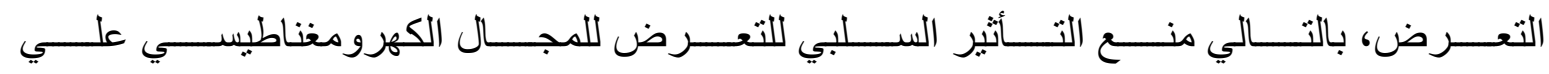

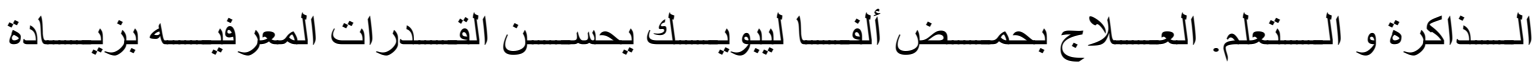

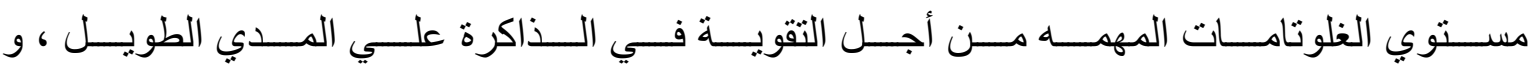
أيضاً يقوم بنقص مستوي دلالات الإجهاد العصبي في الحصين. 